\title{
Perbandingan Metode Multifactor Evaluation Process dan Analytical Hierarchy Process Studi Kasus: Promosi Jabatan di Biro Kepegawaian Institut Teknologi Nasional Bandung
}

\author{
UUNG UNGKAWA ${ }^{1}$, RIDHO FARUQI ${ }^{2}$, NUR FITRIANTI $F^{3}$
}

Program Studi Informatika Institut Teknologi Nasional Bandung

Email: uung@itenas.ac.id

Received9 Agustus 2019 | Revised 30 Agustus 2019 | Accepted 20 September 2019

\begin{abstract}
ABSTRAK
Dalam sistem pendukung keputusan, banyak dijumpai metode untuk mengevaluasi pilihan dalam mengambil keputusan. Dua di antaranya adalah metode Multifactor Evaluation Process (MFEP) dan Analytical Hierarchy Process (AHP). Dalam paper ini disajikan perbandingan keduanya baik secara prosedural maupun hasil akhir dalam pemberian peringkat karyawan di Biro Kepegawaian Institut Teknologi Nasional (Itenas) Bandung. Hasil menunjukkan, bahwa metode AHP lebih komplek dibanding MFEP sedangkan hasil pemeringkatan diperoleh perbedaan di peringkat empat dan lima dari lima karyawan yang dievaluasi.
\end{abstract}

Kata kunci: Multifactor Evaluation Process, Analytical Hierarchy Process, sistem pendukung keputusan.

\begin{abstract}
There are many methods in the decision support system to evaluate candidates to select the best one of them to promote to a position. Two of them are Multifactor Evaluation Process (MFEP) and Analytical Hierarchy Process (AHP). This work compares the two methods both in the procedural point of view of how the decision is made and in the final result of evaluation in the ranking of the employees of Biro Kepegawaian Institut Teknologi Nasional (Itenas) Bandung. The process of calculation shows that AHP more complicated than MFEP, but the rangking of the two methods show similar result except in the 4th and 5th rank between five employees.
\end{abstract}

Keywords: Multifactor Evaluation Process, Analytical Hierarchy Process, decision support system. 


\section{PENDAhUluan}

Setiap hari kita dihadapkan pada persoalan pengambilan keputusan dari yang sederhana seperti menu apa yang akan kita buat hari ini sampai pada persoalan besar seperti bagaimana mengambil strategi untuk keluar dari krisis ekonomi. Sebelum hadirnya sistem pendukung pengambilan keputusan (SPK) berbasis komputer (Decision Support System, DSS) yang mulai dirintis awal 1970an (Power, 2002), pengambilan keputusan dilakukan secara manual dengan mempertimbangkan berbagai aspek atau kriteria. Untuk menentukan siapa yang paling pantas menduduki jabatan tertentu misalnya, dipilih kriteria karyawan seperti disiplin, kemampuan, tingkat pendidikan dan sebagainya. Jika kriteria itu sedikit dan calon yang dipilih juga sedikit, proses pengambilan keputusan bisa lebih sederhana. Akan tetapi jika kriteria dan kandidat lebih besar jumlahnya, maka proses pengambilan keputusan tidak sederhana. Di sinilah pentingnya peranan SPK berbasis komputer.

Dalam penelitian ini diambil studi kasus penentuan karyawan untuk promosi jabatan di biro sumder daya manusia di Institut Teknologi Nasional (Itenas) Bandung. Sebelumnya, setiap kali ada promosi jabatan, pemilihan karyawan yang tepat dilakukan secara manual dengan mengambil kriteria disiplin, pleyanan, kemampuan, sikap dan kehadiran. Kriteria tersebut memiliki bobot berbeda tergantung pada posisi dan ditentukan secara subjektif dan intuitif. Di samping untuk keperluan membantu mempermudah dan otomatisasi proses pengambilan keputusan, dalam penelitian ini juga dimaksudkan untuk mengetahui kinerja dua metode dalam pengambilan keputusan yaitu Multifactor Evaluation Process (MFEP) (Jazuli, Nurkamid, \& Hakim, 2018) (Diwanda et al., 2016) dan Analytical Hierarchy Process (AHP) (R. W. Saaty, 1987), (T. L. Saaty, 1994).

\section{TINJAUAN PUSTAKA}

Umumnya pengambilan keputusan dihadapkan pada persoalan memilih alternatif di antara sekian banyak alternatif, berdasarkan sejumlah kriteria. Semakin banyak alternatif dan kriteria, pengambilan keputusan akan semakin rumit, kompleks. Di sinilah pentingnya peranan sistem pendukung pengambilan keptusan atau lazim disebut sistem pendukung keputusan. Bagian ini menyajikan beberapa penerapan kedua metode yang dipakai dalam penelitian ini, yakni metode AHP dan MFEP. Dalam literatur (Triantaphyllou, 2000), metode MFEP ini dikenal sebagai WSM (Weighted Sum Mode).

Dalam kasus penerimaan karyawan, Azman dan Made menggunakan metode AHP dan MFEP (Maricar \& Sudarma, 2016). Sri Wahyuni menerapkan metode MFEP dalam pemilihan kontraktor pada proyek semenisasi jalan di Kabupaten Kutai Kertanegara (Priyanti, Astuti, \& Khairina, 2016). Yogi dan Veradilla menggunakan metode MFEP untuk pemilihan tanaman pangan di Kabupaten Musi Rawas (Primadasa \& Amalia, 2017). Aan dkk menggunakan metode WSM untuk penentuan peserta jaminan kesehatan masyarakat (Aan dkk., 2017). Wahyu dkk menggunakan WSM untuk pencarian (pemilihan) universitas di Malang (Kurniawan, dkk, 2019).

Metode AHP termasuk metode yang sangat populer karena banyak diterapkan dalam sistem pendukung keputusan. Dua paper yang lain selain yang disebutkan di atas, adalah peningkatan proses pemilihan fakultas (Grandzol, 2005) dan pemilihan bibit ternak sapi potong dengan metode AHP dan MFEP (Afrisawati \& Irianto, 2019). 


\section{METODE PENELITIAN}

Metode yang digunakan dalam penelitian ini adalah pertama, melakukan wawancara untuk mendapatkan informasi tentang penilaian karyawan dan kriteria apa saja yang digunakan dalam promosi jabatan tertentu. Kedua, membangun aplikasi berbasis web untuk mengimplementasikan kedua metode pengambilan keputusan dan menguji aplikasi untuk memastikan kebenarannya. Ketiga, melakukan pemeringkatan karyawan yang paling sesuai untuk menduduki jabatan (posisi) yang akan ditempati dengan kedua metode: MFEP dan AHP. Keempat, membandingkan hasil pemeringkatan dari kedua metode tersebut.

Pada bagian ini menyajikan bagaimana metode MFEP dan AHP melakukan komputasi dalam pemeringkatan untuk membantu seseorang mengambil/membuat keputusan. Data yang digunakan diperoleh dari kepegawaian Itenas. Ada 10 kandidat (karyawan) yang mungkin untuk menduduki posisi tertentu, yang disimbolkan dengan A01, sampai dengan A10. Sub bagian berikut memperlihatkan tahapan komputasi dalam MFEP dan AHP.

\subsection{Tahapan Perhitungan MFEP}

Langkah-langkah pemecahan masalah dalam MFEP adalah sebagai berikut:

1. Menentukan faktor dan bobot faktor dimana total pembobotan harus sama dengan satu ( $\Sigma$ pembobotan = 1), yaitu factor weight. Faktor bobot dapat dilihat pada Tabel 1 .

Tabel 1. Tabel bobot faktor

\begin{tabular}{|l|l|l|l|}
\hline No & Nama kriteria & Bobot (100) & Bobot (1) \\
\hline 1 & Disiplin & 20 & 0,20 \\
\hline 2 & Pelayanan & 35 & 0,35 \\
\hline 3 & Kemampuan & 20 & 0,20 \\
\hline 4 & Sikap & 10 & 0,10 \\
\hline 5 & Kehadiran & 15 & 0,15 \\
\hline \multicolumn{2}{|l|}{ Total $\Sigma W j$} & 100 & 1.00 \\
\hline
\end{tabular}

2. Mengisikan nilai untuk setiap sub faktor yang mempengaruhi dalam pengambilan keputusan dari data-data yang akan diproses untuk Disiplin, Pelayanan, Kemampuan, Sikap dan Kehadiran seperti dalam Tabel 2.

Tabel 2. Rentang Nilai kriteria

\begin{tabular}{|l|l|l|l|}
\hline No & Kriteria & Kategori & Nilai \\
\hline \multirow{4}{*}{1} & \multirow{3}{*}{ Disiplin, Pelayanan, Kemampuan, Sikap, Kehadiran } & Sangat baik & $90-100$ \\
\cline { 3 - 4 } & & Baik & $80-<90$ \\
\cline { 3 - 4 } & & Cukup baik & $70-<80$ \\
\cline { 3 - 4 } & Kurang baik & $60-<70$ \\
\cline { 3 - 4 } & Tidak baik & $<60$ \\
\hline
\end{tabular}

3. Rekap Nilai lima orang kandidat terlihat seperti pada Tabel 3. 
Ungkawa, dkk

Tabel 3. Nilai (Evaluasi) Para Kandidat

\begin{tabular}{|l|l|l|l|l|l|}
\hline Kandidat & Disiplin & Pelayanan & Kemampuan & Sikap & Kehadiran \\
\hline A01 & 100 & 100 & 100 & 100 & 95 \\
\hline A02 & 80 & 90 & 100 & 90 & 90 \\
\hline A03 & 90 & 70 & 80 & 90 & 95 \\
\hline A04 & 80 & 70 & 100 & 90 & 95 \\
\hline A05 & 100 & 70 & 60 & 80 & 75 \\
\hline
\end{tabular}

Proses perhitungan weight x evaluation yang merupakan proses perkalian bobot dengan nilai, kemudian hasil totalnya dengan menjumlahan seluruh hasil perkalian bobot-nilai untuk tiap kandidat seperti pada

\section{Tabel 4:}

$>$ Bobot $\times$ Nilai disiplin :

$\begin{array}{lll}w_{A 01} & =100 * 0.2=20 \\ w_{A 02} & =80 * 0.2 & =16 \\ w_{A 03} & =90 * 0.2 & =18 \\ w_{A 04} & =80 * 0.2 & =16 \\ w_{A 05} & =100 * 0.2 & =20\end{array}$

$>$ Bobot $x$ Nilai pelayanan :

$\begin{array}{lll}w_{\mathrm{A} 01} & =100 * 0.35=35 \\ w_{\mathrm{A} 02} & =90 * 0.35=31.5 \\ w_{\mathrm{A} 03} & =70 * 0.35=24.5 \\ w_{\mathrm{A} 04} & =70 * 0.35=24.5 \\ w_{\mathrm{A} 05} & =70 * 0.35=24.5\end{array}$

Bobot $x$ Nilai kemampuan :

$\begin{array}{rrr}w_{\mathrm{A} 01}=100 * 0.2=20 & \\ w_{\mathrm{A} 02} & =100 * 0.2=20 \\ w_{\mathrm{A} 03} & =80 * 0.2=16 \\ w_{\mathrm{A} 04} & =100 * 0.2=20 \\ w_{\mathrm{A} 05} & =60 * 0.2=16\end{array}$

Bobot $x$ Nilai sikap :

$\begin{array}{lll}w_{\mathrm{A} 01} & =100 * 0.1 & =10 \\ w_{\mathrm{A} 02} & =90 * 0.1 & =9 \\ w_{\mathrm{A} 03} & =90 * 0.1 & =9 \\ w_{\mathrm{A} 04} & =90 * 0.1 & =9 \\ w_{\mathrm{A} 05} & =80 * 0.1 & =8\end{array}$

Bobot $x$ Nilai kehadiran :

$\begin{array}{lll}w_{\mathrm{A} 01} & =95 * 0.15 & =14.25 \\ w_{\mathrm{A} 02} & =90 * 0.15 & =13.5 \\ w_{\mathrm{A} 03} & =95 * 0.15 & =14.5 \\ w_{\mathrm{A} 04} & =95 * 0.15 & =14.5 \\ w_{\mathrm{A} 05} & =75 * 0.15 & =11.25\end{array}$


Tabel 4. Nilai Bobot x Nilai

\begin{tabular}{|l|l|l|l|l|l|l|}
\hline No & Nama & Disiplin & Pelayanan & Kemampuan & Sikap & Kehadiran \\
\hline 1 & A01 & 20 & 35 & 20 & 10 & 14.25 \\
\hline 2 & A02 & 16 & 31.5 & 20 & 9 & 13.5 \\
\hline 3 & A03 & 18 & 24.5 & 16 & 9 & 14.25 \\
\hline 4 & A04 & 16 & 24.5 & 20 & 9 & 14.25 \\
\hline 5 & A05 & 20 & 24.5 & 12 & 8 & 11.25 \\
\hline
\end{tabular}

5. Menjumlahkan seluruh hasil Bobot $x$ Nilai untuk memperoleh total hasil evaluasi:
1) $\sum W_{\mathrm{A} 01}$
$=20+35+20+10+14.25$
$=99.25$
2) $\sum W_{\mathrm{A} 02}$
$=16+31.5+20+9+13.5$
$=90$
3) $\sum W_{\mathrm{A} 03}$
$=18+24.5+16+9+14.25$
$=81.75$
4) $\sum W_{\mathrm{A} 04}$
$=16+24.5+20+9+14.25$
$=83.75$
5) $\sum W_{\mathrm{A} 05}$
$=20+24.5+12+8+11.25$
$=75.75$

6. Setelah menjumlahkan seluruh hasil weight evaluation maka akan diperoleh hasil akhir yang dapat dijadikan rangking seperti pada Tabel 5 .

Tabel 5. Peringkat Karyawan

\begin{tabular}{|l|l|l|l|}
\hline No & Nama & Total & Rank \\
\hline 1 & A01 & 99.25 & 1 \\
\hline 2 & A02 & 90 & 2 \\
\hline 3 & A04 & 83.75 & 3 \\
\hline 4 & A03 & 81.75 & 4 \\
\hline 5 & A05 & 75.75 & 5 \\
\hline
\end{tabular}

\subsection{Tahapan perhitungan AHP}

Perhitungan AHP dimulai dengan pembuatan matriks hirarki antar kriteria, yang merupakan matrik perbandingan antar kriteria. Pembuatan matriks berdasarkan acuan pada skor penilaian Tabel 1. Hasil penilaian menggunakan matriks perbandingan dapat dilihat dalam Tabel 6 .

Tabel 6. Matriks Perbandingan

\begin{tabular}{|l|l|l|l|l|l|}
\hline \multicolumn{7}{|c|}{ MATRIX PERBANDINGAN } \\
\hline & Disiplin & Pelayanan & Kemampuan & Sikap & Kehadiran \\
\hline Disiplin & 1 & 0.33 & 1 & 5 & 3 \\
\hline pelayanan & 3 & 1 & 3 & 7 & 5 \\
\hline Kemampuan & 1 & 0.33 & 1 & 5 & 3 \\
\hline Sikap & 0.20 & 0.14 & 0.20 & 1 & 0.33 \\
\hline Kehadiran & 0.33 & 0.20 & 0.33 & 3 & 1 \\
\hline Jumlah & 5.533 & 2.01 & 5.533 & 21 & 12.333 \\
\hline
\end{tabular}


Tabel 7. Skala Nilai Perbandingan

\begin{tabular}{|l|l|l|}
\hline Tingkat Kepentingan & Nilai & Keterangan \\
\hline Sama-sama penting & 1 & dua kegiatan (kriteria) memberi sumbangan sama pada tujuan. \\
\hline Sedang, lebih penting & 3 & $\begin{array}{l}\text { Pengalaman dan pertimbangan agak lebih disukai dibanding } \\
\text { yang lain }\end{array}$ \\
\hline Sangat penting & 5 & $\begin{array}{l}\text { Pengalaman dan pertimbangan sangat penting/sangat disukai } \\
\text { dibanding yang lain }\end{array}$ \\
\hline Amat sangat penting & 7 & $\begin{array}{l}\text { Pengalaman dan pertimbangan amat sangat disukai dibanding } \\
\text { yang lain }\end{array}$ \\
\hline $\begin{array}{l}\text { Terlalu amat sangat } \\
\text { penting }\end{array}$ & 9 & $\begin{array}{l}\text { Pengalaman dan pertimbangan terlalu amat sangat disukai } \\
\text { dibanding yang lain }\end{array}$ \\
\hline & $2,4,6,8$ & Untuk mencari kompromi di antara nilai di atas \\
\hline
\end{tabular}

Dalam Tabel 6 nilai perbandingan antar kriteria tergantung hirarki dan seberapa besar tingkat kepentingannya. Kriteria dengan nilai lebih kecil berarti tingkat kepentingannya pada hierarki dibawah dari kriteria yang memilki nilai lebih besar. Dalam AHP, nilai perbandingan tingkat kepentingan tampak seperti pada

Tabel 7. Sebagai contoh, nilai disiplin 3 terhadap kehadiran, artinya disiplin lebih penting dari pada kehadiran dalam hierarki penilaian kriteria. Setelah didapatkan perbandingan kepentingan maka dilakukan sintesa dengan menjumlahkan setiap kolom (Tabel 5). Langkah berikutnya, normalisasi dengan cara membagi setiap sel dengan jumlah pada kolom yang bersangkutan. Hasil normalisasi ditunjukan pada Tabel $\boldsymbol{8}$.

Tabel 8. Hasil Normalisasi Kriteria

\begin{tabular}{|l|l|l|l|l|l|}
\hline & Disipin & Pelayanan & Kemampuan & Sikap & Kehadiran \\
\hline Disiplin & 0.18 & 0.17 & 0.18 & 0.23 & 0.24 \\
\hline Pelayanan & 0.54 & 0.50 & 0.54 & 0.3 & 0.54 \\
\hline Kemampuan & 0.18 & 0.17 & 0.18 & 0.23 & 0.24 \\
\hline Sikap & 0.03 & 0.07 & 0.03 & 0.04 & 0.02 \\
\hline Kehadiran & 0.06 & 0.10 & 0.06 & 0.14 & 0.08 \\
\hline
\end{tabular}

Setelah dinormalisasi kemudian dihitung rata-rata setiap alternatif untuk menghasilkan Priority Vector/Bobot. Priority Vector dapat dilihat pada Tabel 9. Nilai priority vector didapatkan dari ratarata dari nilai masing-masing baris, sebagai contoh 0.201732 didapatkan dari, Priority vector $=0.180723+0.17+0.180722892+0.238+0.2432432=0.201732$.

Tabel 9. Priority Vector

\begin{tabular}{|l|c|r|r|r|r|c|}
\hline & Disiplin & Pelayanan & Kemampuan & Sikap & Kehadiran & $\begin{array}{c}\text { Priority } \\
\text { vector }\end{array}$ \\
\hline Disiplin & 0.18 & 0.17 & 0.18 & 0.23 & 0.24 & 0.20 \\
\hline pelayanan & 0.54 & 0.50 & 0.54 & 0.33 & 0.40 & 0.46 \\
\hline
\end{tabular}


Perbandingan Metode Multifactor Evaluation Proccess dan Analytical Hierarchy Proccess

\begin{tabular}{|l|l|l|l|l|l|l|}
\hline kemampuan & 0.18 & 0.17 & 0.18 & 0.23 & 0.24 & 0.20 \\
\hline sikap & 0.03 & 0.07 & 0.03 & 0.04 & 0.02 & 0.04 \\
\hline kehadiran & 0.06 & 0.10 & 0.06 & 0.14 & 0.08 & 0.08 \\
\hline
\end{tabular}

Priority Vector menunjukkan bobot dari masing-masing kriteria, jadi dalam hal ini pelayanan merupakan bobot tertinggi/terpenting dalam perangkingan karyawan. Selanjutnya menghitung rasio konsistensi dari priority vector (Bobot) yang didapatkan.

Pertama melakukan perkalian matriks antara matriks perbandingan pada Tabel $\boldsymbol{\sigma}$ dan Priority Vector pada Tabel 9. Hasil perkalian dilihat pada Tabel 10.

Tabel 10. Hasil Perkalian

\begin{tabular}{|l|l|l|l|l|l|l|l|}
\hline & Disiplin & Pelayanan & Kemampuan & Sikap & Kehadiran & $\begin{array}{l}\text { Priority } \\
\text { vector }\end{array}$ & $\begin{array}{l}\text { Hasil } \\
\text { perkalian }\end{array}$ \\
\hline Disiplin & 1 & 0.33 & 1 & 5 & 3 & 0.20 & 1.04 \\
\hline pelayanan & 3 & 1 & 3 & 7 & 5 & 0.46 & 2.42 \\
\hline kemampuan & 1 & 0.33 & 1 & 5 & 3 & 0.20 & 1.04 \\
\hline sikap & 0.20 & 0.14 & 0.20 & 1 & 0.33 & 0.04 & 0.2 \\
\hline kehadiran & 0.33 & 0.20 & 0.33 & 3 & 1 & 0.08 & 0.44 \\
\hline
\end{tabular}

Nilai hasil perkalian tersebut didapat dari perkalian matriks, sebagai contoh 1.04 didapatkan dari $1 * 0.201732+0.33 * 0.464141+1 * 0.201732+5 * 0.043605+3 * 0.088789=$ $1.042571=1.04$.

Hasil perkalian tersebut lalu dibagi dengan Priority Vector. Hasilnya pada Tabel 11.

Tabel 11. Hasil Perkalian Dibagi Priority Vector

\begin{tabular}{|l|l|l|}
\hline Hasil Perkalian & Priority Vector & $\begin{array}{l}\text { Hasil Kali / Priority } \\
\text { Vector }\end{array}$ \\
\hline 1.042571 & 0.201732 & 5.16809485 \\
\hline 2.423716 & 0.464141 & 5.22193613 \\
\hline 1.042571 & 0.201732 & 5.16809485 \\
\hline 0.2202 & 0.043605 & 5.04987891 \\
\hline 0.446921 & 0.088789 & 5.03350168 \\
\hline
\end{tabular}

Selanjutnya mencari Eigen Max dengan persamaan berikut:

$\operatorname{Imax}=\frac{5.16809485+5.22193613+5.16809485+5.04987891+5.03350168}{5}=5.128301$

Setelah menghitung Imax, selanjutnya menghitung Consistency Index (CI). Menghitung CI menggunakan persamaan berikut.

$$
\mathrm{CI} \quad=\frac{\operatorname{Imax}-n}{n-1}=\frac{5.128301-5}{5-1}=0.032075321
$$

Kemudian menghitung Consistency Ratio (CR) berdasarkan nilai Index Random (IR) pada Tabel 12 diperoleh dengan rumus:

$$
\mathrm{CR} \quad=\frac{C I}{I R}=\frac{0.032075321}{1,12}=0.0286
$$


Tabel 12. Index Random

\begin{tabular}{|l|l|l|l|l|l|l|l|l|l|l|}
\hline $\mathbf{n}$ & $\mathbf{1}$ & $\mathbf{2}$ & $\mathbf{3}$ & $\mathbf{4}$ & $\mathbf{5}$ & $\mathbf{6}$ & $\mathbf{7}$ & $\mathbf{8}$ & $\mathbf{9}$ & $\mathbf{1 0}$ \\
\hline IR & 0,00 & 0,00 & 0,58 & 0,90 & 1,12 & 1,24 & 1,32 & 1,41 & 1,45 & 1,49 \\
\hline
\end{tabular}

Hasil perhitungan $\mathrm{CR}<=0,1$, maka rasio konsistensi dari bobot prioritas dapat diterima. Maka Bobot Kriteria menjadi bobot tertinggi/terpenting. Langkah selanjutnya adalah mencari nilai rata - rata atau Prioity Vector (PV) pada setiap kriteria dan data alternatif. Untuk kriteria disiplin, tampak seperti pada Tabel 13.

Tabel 13. PV Disiplin

\begin{tabular}{|l|r|r|r|r|r|}
\hline Disiplin & \multicolumn{1}{|l|}{ A01 } & \multicolumn{1}{|l|}{ A02 } & \multicolumn{1}{c|}{ A03 } & \multicolumn{1}{c|}{ A04 } & \multicolumn{1}{c|}{ A05 } \\
\hline A01 & 1.00 & 5.00 & 5.00 & 3.00 & 1.00 \\
\hline A02 & 0.20 & 1.00 & 1.00 & 0.33 & 0.20 \\
\hline A03 & 0.20 & 1.00 & 1.00 & 0.33 & 0.20 \\
\hline A04 & 0.33 & 3.00 & 3.00 & 1.00 & 0.33 \\
\hline A05 & 1.00 & 5.00 & 5.00 & 3.00 & 1.00 \\
\hline
\end{tabular}

Tabel 13 menjelaskan bahwa karyawan yang mendapatkan nilai lebih kecil berarti nilai kinerjanya di bawah dari karyawan yang memilki nilai lebih besar. Sebagai contoh data A01 kinerja disiplinnya 5 terhadap A02, artinya performa A01 lebih baik dari pada A02.

Langkah selanjutnya adalah melakukan normalisasi nilai dengan melakukan fungsi pembagian dari rata-rata setiap kolom data alternatif dengan nilai setiap data alternatif. Contoh untuk kriteria disiplin, tampak seperti pada Tabel 14:

Tabel 14. Normalisasi Nilai Data Alternatif

\begin{tabular}{|l|l|l|l|l|l|r|}
\hline $\begin{array}{l}\text { Normalisasi } \\
\text { disiplin }\end{array}$ & A01 & A02 & A03 & A04 & A05 & $\begin{array}{l}\text { Rata-rata } \\
\text { vektor }\end{array}$ \\
\hline A01 & 0.365 & 0.333 & 0.333 & 0.391 & 0.365 & 0.357 \\
\hline A02 & 0.073 & 0.066 & 0.066 & 0.043 & 0.073 & 0.064 \\
\hline A03 & 0.073 & 0.066 & 0.066 & 0.043 & 0.073 & 0.064 \\
\hline A04 & 0.121 & 0.200 & 0.200 & 0.130 & 0.121 & 0.154 \\
\hline A05 & 0.365 & 0.333 & 0.333 & 0.391 & 0.365 & 0.357 \\
\hline
\end{tabular}

Setelah didapatkan normalisasi data maka langkah selanjutnya yang akan dilakukan adalah perangkingan karyawan. Perangkingan karyawan dilakukan dengan cara mengambil setiap data priority vector lalu mengkali matriks dengan data alternatif, seperti pada Tabel 15.

$$
\text { Hasil akhir }=\left[\begin{array}{lllll}
A & B & C & D & E \\
A & B & C & D & E
\end{array}\right] \times\left[\begin{array}{l}
A \\
B
\end{array}\right]
$$

Tabel 15. Hasil Akhir Perhitungan AHP

\begin{tabular}{|l|c|c|l|l|l|c|c|}
\hline & disiplin & pelayanan & kemampuan & sikap & kehadiran & $\begin{array}{c}\text { Priority } \\
\text { vector }\end{array}$ & $\begin{array}{c}\text { Hasi } \\
\text { akhir }\end{array}$ \\
\hline A01 & 0.357 & 0.523 & 0.297 & 0.441 & 0.283 & 0.20 & 0.419 \\
\hline
\end{tabular}


Perbandingan Metode Multifactor Evaluation Proccess dan Analytical Hierarchy Proccess

\begin{tabular}{|l|l|l|l|l|l|l|l|}
\hline A02 & 0.064 & 0.281 & 0.297 & 0.165 & 0.114 & 0.46 & 0.220 \\
\hline A03 & 0.064 & 0.0649 & 0.297 & 0.165 & 0.283 & 0.20 & 0.135 \\
\hline A04 & 0.154 & 0.064 & 0.078 & 0.165 & 0.283 & 0.04 & 0.109 \\
\hline A05 & 0.357 & 0.064 & 0.02 & 0.063 & 0.035 & 0.08 & 0.114 \\
\hline
\end{tabular}

\section{HASIL DAN PEMBAHASAN}

Setelah dilakukan perhitungan, selanjutnya dilakukan perbandingan peringkat hasil dari perhitungan yang dilakukan oleh sistem pendukung keputusan dengan metode MFEP dan AHP, untuk menguji performa dari sistem yang dibuat. Tabel 16 merupakan perbandingan peringkat hasil dari perhitungan yang dilakukan oleh kedua sistem.

Skenario pengujian performa sistem yang dilakukan sebagai berikut.

1. Menghitung menggunakan program aplikasi.

2. Membandingkan hasil perhitungan aplikasi dari metode AHP dan MFEP

Tabel 16. Perbandingan Hasil Pemeringkatan

\begin{tabular}{|l|l|l|l|l|}
\hline Alternatif & Hasil MFEP & Rank MFEP & Hasil AHP & Rank AHP \\
\hline A01 & 99.25 & 1 & 0.419 & 1 \\
\hline A02 & 90 & 2 & 0.220 & 2 \\
\hline A03 & 83.75 & 3 & 0.135 & 3 \\
\hline A04 & $\mathbf{8 1 . 7 5}$ & $\mathbf{4}$ & $\mathbf{0 . 1 0 9}$ & $\mathbf{5}$ \\
\hline A05 & $\mathbf{7 5 . 7 5}$ & $\mathbf{5}$ & $\mathbf{0 . 1 1 4}$ & $\mathbf{4}$ \\
\hline
\end{tabular}

Berdasarkan perhitungan dengan aplikasi, terdapat perbedaan hasil antara metode AHP dan MFEP, yaitu pada data uji A04 dan A05 sedangkan rangking satu sampai dengan tiga kedua metode memberi hasil pemeringkatan yang sama. Hal ini disebabkan beberapa faktor diantaranya adalah :

1. Perbedaan hasil terjadi dikarenakan metode AHP menggunakan sistem hierarki berdasarkan tingkat kepentingannya, sehingga data nilai alternatif diubah menjadi tingkat hierarki. Sedangkan pada metode MFEP data nilai alternatif tidak dilakukan proses apapun;

2. Pada metode AHP bobot kriteria juga diubah menjadi skala prioritas berdasarkan tingkat kepentingannya dalam hierarki, sedangkan pada metode MFEP bobot kriteria tidak dilakukan perubahan dengan proses apapun;

3. Perbedaan juga terjadi karena pada metode AHP setiap alternatif dibandingkan satu dengan yang lainnya seperti pada Tabel 13. data alternatif A01 dibandingkan terhadap A02, A03, A04, A05, dan begitu juga pada data alternatif yang lainnya dibandingkan satu dengan yang lainnya.

\section{KESIMPULAN}

Berdasarkan implementasi dan pengujian, maka dapat ditarik kesimpulan sebagai berikut : 
1. Sistem dapat menampilkan data ranking karyawan sebagai nilai akhir, dengan menggunaan metode MFEP dan AHP.

2. Sistem diimplementasikan dengan menggunakan kriteria dan bobot yang diberikan oleh instansi terkait yaitu Biro Kepegawaian Itenas;

3. Perbedaan antara hasil metode MFEP dan AHP terjadi karena pada AHP nilai bobot dan nilai alternatif diubah menjadi skala prioritas sedangkan pada metode MFEP nilai bobot dan alternatif tidak dirubah.

\section{UCAPAN TERIMA KASIH}

Terimakasih ditujukan kepada Biro Kepegawaian Itenas yang sudah membantu memberikan data dan informasi untuk kepentingan penelitian.

\section{DAFTAR RUJUKAN}

Aan, M., Gienam, S., Nasution, S. D., Putera, A., Siahaan, U., Pembangunan, U., \& Budi, P. (2017). PENERAPAN WEIGHTED SUM MODEL (WSM) DALAM PENENTUAN PESERTA JAMINAN KESEHATAN MASYARAKAT. Jurnal Riset Sistem Informasi Dan Teknik Informatika (JURASIK), O2(July). https://doi.org/10.30645/jurasik.v2i1.17

Afrisawati, \& Irianto. (2019). PEMILIHAN BIBIT TERNAK SAPI POTONG MELALUI KOMBINASI METODE AHP DAN METODE MFEP. Jurnal Teknologi Dan Sistem Informasi, VI(1), 43-50.

Diwanda, S. A., Ode, L., Sagala, H. S., Informatika, J. T., Teknik, F., \& Oleo, U. H. (2016). Sistem pendukung keputusan penilaian kinerja karwayan menggunakan metode. 2(1), 341-348.

Grandzol, J. R. (2005). Improving the Faculty Selection Process in Higher Education: A Case for the Analytic Hierarchy Process. IR Applications.

Jazuli, A., Nurkamid, M., \& Hakim, M. M. (2018). Multifactor Evaluation Process for the Determination of Aid Restoration Home. https://doi.org/10.4108/eai.24-102018.2280509

Kurniawan, W. A., Putra, N. P., Pradana, R. P., Ulum, M., \& Almais, A. T. W. (2019). SISTEM PENDUKUNG KEPUTUSAN PENCARIAN UNIVERSITAS DI MALANG MENGGUNAKAN WEIGHT PRODUCT DENGAN PEMBOBOTAN WEIGHTED. Jurnal IImiah Informatika, 4(2), 103-110.

Maricar, M. A., \& Sudarma, M. (2016). Decision Support System of the Employees Acceptance using Analytical Hierarchy Process ( AHP ) and Multi Factor Evaluation Process ( MFEP ). International Journal of Engineering and Emerging Technology, 1(December).

Power, D. J. (2002). Decision Support Systems: Concepts and Resources for Managers. In Information Systems Management (Vol. 20). Quorum Books. 
Primadasa, Y., \& Amalia, V. (2017). Penerapan Metode Multi Factor Evaluation Process untuk Pemilihan Tanaman Penerapan Metode Multi Factor Evaluation Process untuk Pemilihan Tanaman Pangan di Kabupaten Musi Rawas. Jurnal Sisfo, OЛ(September 2017). https://doi.org/10.24089/j.sisfo.2017.09.004

Priyanti, S. W., Astuti, I. F., \& Khairina, D. M. (2016). Penerapan Multifactor Evaluation Process (Mfep) Untuk Pemilihan Kontraktor Pada Proyek Semenisasi Jalan (Studi Kasus: Unit Layanan Pengadaan Kabupaten Kutai Kartanegara). Prosiding Seminar Sains Dan Teknologi FMIPA Unmul.

Saaty, R. W. (1987). The analytic hierarchy process-what it is and how it is used. Mathematical Modelling, 9(3-5), 161-176. https://doi.org/10.1016/0270-0255(87)90473-8

Saaty, T. L. (1994). How to Make a Decision : The Analytic Hierarchy Process. Interfaces, 24(6), $19-43$.

Triantaphyllou, E. (2000). Multi-Criteria Decision Making Methods: A Comparative Study. https://doi.org/10.1007/978-1-4757-3157-6 